\title{
Fall determinants and home modifications by occupational therapists to prevent falls
}

\author{
Abstract \\ Background: Approximately one third of older people over 65 fall each year. Purpose: \\ To determine the risk factors of falls for frail older persons and to evaluate the impact of home \\ modifications by an occupational therapist on the risk of falls from a longitudinal study. Method: \\ All participants were at least 65 years old and were assessed at the start and in the first six \\ months of the intervention. Bivariate analysis and logistic regression models were used to study \\ the risk factors of falls and the effect of home modifications on the incidence of falls. Findings: \\ The main predictors of falls in this study were vision problems, distress of informal caregiver \\ and insufficient informal support. Home modifications provided by an occupational therapist \\ showed a significant reduction of falls. Implications: Informal caregivers and their health status \\ had an impact on the fall risk of frail older persons. Home modifications by an occupational \\ therapist reduced the fall risk of frail older persons at six months follow-up.
}

\section{Key words}

Falling - Occupational Therapy - Fall determinants - Home modifications - Older adults

\section{Background}

Aging is becoming a challenge for most societies across the world. In Belgium, the percentage of people over 65 was $15.03 \%$ in 1995 and is estimated to reach $25.76 \%$ by 2060 according to the Federal Public Service of economy. Moreover, the percentage of people over 80 will go from $3.6 \%$ to $10.7 \%$ between 2000 and 2050 (Andresen \& Puggaard, 2008; Fontaine \& Jans, 2009; Trottier, Martel, Houle, Berthelot, \& Legare, 2000). Ageing is correlated with a greater risk of being confronted with one or more chronic diseases, which reduce quality of life and increase frailty (Ferrucci, Giallauria, \& Guralnik, 2008). These chronic illnesses affecting 
older persons (somatic diseases, behavioral health problems, cognitive and other functional limitations) are likely to lead to geriatric syndromes and falls, one of the most compelling risk factors that can lead to mortality (Anderson, Goodman, Holtzman, Posner, \& Northridge, 2012). Geriatric syndrome is used to characterize multifactorial conditions such as delirium, incontinence, frailty and falls (Inouye, Studenski, Tinetti, \& Kuchel, 2007; Strandberg, Pitkälä, Tilvis, O’Neill, \& Erkinjuntti, 2013).

Approximately one third of older people over 65 fall each year. This proportion increases with age (Fletcher \& Hirdes, 2002). Falling is an important risk factor for fractures, development of traumatic cerebral or visceral hemorrhage, traumatic pain syndromes, functional limitations, dislocations and soft tissue injuries, which often cause hospitalization and institutionalization (Masud \& Morris, 2001; Peel, 2011; Rubenstein, 2006). About 10-15\% of the falls in older people living at home and $15-20 \%$ of falls in institutionalized patients result in significant injuries (Karlsson, Magnusson, von Schewelov, \& Rosengren, 2013; Tinetti, Liu, \& Ginter, 1992). Falling can cause substantial disability, morbidity and mortality amongst older people. Falling can be caused by multiple factors, some of which are intrinsic, such as old age, musculoskeletal diseases, gait and balance disorders, while others are extrinsic environmental hazards, such as slippery floors, rugs, poor lighting, chairs and armchairs without handrails (Cameron et al., 2010; Gillespie et al., 2009, 2012; Tinetti, Doucette, Claus, \& Marottoli, 1995).

Occupational therapy is considered to be a discipline which helps to prevent falls (Clemson, Mackenzie, Ballinger, Close, \& Cumming, 2008; Walker \& Howland, 1991). When integrated in the client's environment, occupational therapy has shown to be effective. Home modifications are adaptations to the living environment intended to increase ease of use, safety, security and independence. Modifications can include changes in or additions to the structure (e.g., widening doorways, adding a first floor bathroom or a ramp), installing specialized 
equipment (e.g., grab bars and handrails) and adjusting the location of items (e.g., moving furniture). Home modifications overlap considerably with the use of assistive devices (e.g., bath benches, walkers), which tend to be more mobile in nature and not to be attached to the structure of the house. In addition, home modifications are often accompanied by repairs (e.g., fixing worn-out stairs) (Clemson, Mackenzie, Ballinger, Close, \& Cumming, 2008; Tanner, Tilse, \& de Jonge, 2008). A home modification by an occupational therapist led to a reduction of the mortality risk for elderly patients (Gitlin, Hauck, Winter, Dennis, \& Schulz, 2006). Two studies and a systematic review showed that home assessments and home modifications conducted by occupational therapists protected clients from falling (Chase, Mann, Wasek, \& Arbesman, 2012; Johnston, Barras, \& Grimmer-Somers, 2010; Pighills, Torgerson, Sheldon, Drummond, \& Bland, 2011). Moreover, home modification interventions had a positive impact on self-rated ability in everyday life, especially on decreasing the level of difficulty and increasing safety (Petersson, Lilja, Hammel, \& Kottorp, 2008; Stark, Landsbaum, Palmer, Somerville, \& Morris, 2009).

The first purpose of this study is to determine the risk factors for falls in frail older persons living in the community and who have not had a previous fall. It is known that a fall is a high risk factor for a subsequent fall (Fletcher, Berg, Dalby, \& Hirdes, 2009) and this knowledge might lead health professionals to identify risk clients and to make some preventive actions. Literature should also show how to detect the determinants of a first fall (frail older person at risk of falling without any previous fall), in order to implement the first preventive interventions. This paper presents the results which highlight these determinants. The second aim is to evaluate the impact on fall incidence of interventions offering home modifications and advice by occupational therapists in combination or not with case management. According to the current literature occupational therapy seems to be effective as a preventive intervention on 
falls (Chase, Mann, Wasek, \& Arbesman, 2012; Johnston, Barras, \& Grimmer-Somers, 2010; Pighills, Torgerson, Sheldon, Drummond, \& Bland, 2011). Our work extends this literature by investigating the added component of case management and its impact on the results.

\section{Methods}

\section{Design}

This is a longitudinal study based on a quasi-experimental design (Grimshaw, Campbell, Eccles, \& Steen, 2000). The study took place in Belgium between the years 2010 and 2014. During this period, the Belgian National Institute for Health and Disability Insurance (NIHDI) funded 63 projects of which the main purpose was to maintain frail older persons at home for as long as possible, with good quality of life and low informal caregiver's burden. All 63 projects were included in the study but 14 of these projects provided home modifications by an occupational therapist as an intervention: seven projects provided home modifications and seven provided case management support in addition to home modifications. The 49 remaining projects offered other interventions to meet the goal of keeping frail older persons at home. Their interventions could not be classified as occupational therapy. Some examples are day care services, psychosocial interventions and night care at home (reference removed for blinding, 2016).

\section{Research Questions}

What are the determinant factors of falls for frail older people living at home who have no previous falls in the last 90 days before receiving the intervention? (Aim 1)

To explore these determinants, we analyzed a sample which consisted of frail older persons who did not fall in the last 90 days before their start in the intervention (sample 1), being the intervention home modification or not. Thus, from the whole population of the study, we 
excluded people who had fallen before the interventions in order to analyze a population without a high previous risk of falling.

What is the impact of home modifications by an occupational therapist on the risk of falls of frail older people who fell at least once before receiving the intervention and does the combination of home modifications with a case management provide results that differ from those with home modifications without a component of case management? (Aim 2)

For this analysis we had a sample consisting of frail older persons who fell in the last 90 days before participating in the interventions (sample 2). The purpose was to investigate the effectiveness of the interventions offering home modifications by an occupational therapist on the risk of falls of a high risk population which had fallen before so that a subsequent fall could be avoided.

\section{Study Sample and Recruitment}

Both samples used for the analysis come from the same population: frail older people living at home. Participants of the study were at least 65 years old and frail. Frailty was assessed by the Edmonton Frailty Scale (cut off 6 or over) or by a Belgian version of the Katz scale (profiles A, B or C for the 'Home' version and profiles B, C or Cd for the 'Residential' version). Older persons with a dementia diagnosis could also be enrolled in the study. Exclusion criteria were less than 65 years old, no frailty or no dementia diagnosis. The protocol of the research has been published previously (reference removed for blinding, 2012). Clients were recruited by the organizations providing the interventions by means of the needs of these clients. Recruitment could happen after a recommendation from a general practitioner, after a hospital discharge or by home care organizations or social services. From the beginning of the study, each organization had the responsibility of recruiting their own participants according to the inclusion criteria of the study. No randomization in the allocation of participants was possible. 


\section{Informed Consent}

This study was approved by the Belgian Privacy Commission and by the Ethics committee of the Belgian Universities. A formal procedure was implemented so that caregivers could fill out the questionnaires on a secured website. All participants signed an informed consent after meeting the inclusion criteria. In case they were not capable of signing this document, a family member or another legal representative signed it on their behalf, as stipulated by Belgian law. Participants had the right not to participate in the research and could withdraw their consent at any time. All data were anonymized and analyzed according to the rules of the Belgian Privacy Commission.

\section{Intervention Protocol}

To investigate the impact of home modifications by an occupational therapist on falls, we distinguished 3 types of interventions among the 63 projects:

- Interventions providing home modifications at home and advice about assistive devices. The participants in these projects had only occupational therapy at home based on home modifications and advice about assistive devices.

- Interventions combining case management and home modifications and advice about assistive devices. The participants in these projects had home modifications by an occupational therapist, advices about assistive devices and also had a coordination of care insured by a case manager.

- Other interventions not providing any home modifications or advice about assistive devices. This category gathered the participants receiving interventions which did not include any home modifications or advice about assistive devices. Among these projects, some provided psychosocial support at home, others provided night care at home or day care services in a residential setting, among other interventions other than home modifications. These 
interventions were delivered by professional caregivers like nurses, psychologists, educators, but not by occupational therapists.

To fully understand what home modification entailed and to distinguish these three types of interventions, a qualitative analysis was performed to identify the components of the intervention. This qualitative analysis was based on the descriptions provided by the organizations offering interventions by means of a yearly online survey and interviews and also by means of case studies and visits made by the researchers. Each year the 63 projects provided information about their organization and the way they performed and delivered the intervention by an open questionnaire or by an open questionnaire and an interview performed by the scientific consortium. These data provided information for a thorough qualitative analysis which resulted in the classification of the interventions recently published (reference removed for blinding, 2015).

The process of implementing changes in the living environment happened as follows: at the first visit, a comprehensive assessment was filled out (the interRAI HC instrument). Then, the occupational therapist identified the needs and wishes regarding daily activities and leisure activities of the older persons and, if applicable, of their informal caregivers. After that, home visits (two to three depending on the frail older person's situation) was planned and consisted of providing counselling on how to adapt the home or use assistive devices. Then, once the adaptations were made, the occupational therapist taught clients and informal caregivers how to correctly use the new materials or how to adapt to their changed environment. This follow-up was a crucial component in order to allow for optimal use of the changes and to ensure efficacy by means of good adherence (Cumming et al., 2001; Currin, Comans, Heathcote, \& Haines, 2012). 
A control group was created with frail older persons who received the least effective interventions (no home modifications included) in delaying institutionalization and with the lowest costs. These interventions were considered to have a 'zero-effect', since they provided very few services showing no effect on the delay of institutionalization. This control group was an extra group, different from the three other intervention groups previously described and could be considered as a comparison group in which no clients were receiving home modifications. The interventions provided in this comparison group were so low intensive (ex. once every three months) that it was as if clients received no intervention at all. Professional caregivers in the control group also filled out the same assessment instruments for the participants as in the intervention groups.

\section{Assessment/Study Instruments}

In order to collect the data for the study, professional caregivers assessed older persons included with the interRAI Home Care instrument (interRAI HC) during the intervention period which is a validated comprehensive geriatric assessment instrument (Hirdes et al., 2008; Landi et al., 2000). The interRai HC instrument contains items covering several key domains such as cognition, communication, vision, diagnosis, health status, functional condition, psychological and social situation, dental status, skin condition and informal support. It is a person-centered assessment which evaluates the needs and strengths focusing on the person's holistic situation. When the assessment is completed, outcome measures are automatically generated, such as the validated interRAI scales and the Client Assessment Protocols (CAPs), which are measures of potential risk or problem situations which can help to develop a care plan (Carpenter, 2006; Fletcher \& Hirdes, 2002; Vanneste \& Declercq, 2014).

\section{Data collection Protocol}


Professional caregivers from the 63 projects were asked to fill out the interRAI HC at enrollment of frail older person in the intervention (baseline), at exit from the intervention and 6 months after baseline. Additionally, if frail older persons stayed longer than 6 months in the intervention group, caregivers had to do a follow-up every 6 months until the moment the frail older persons stop receiving the intervention. Criteria to exit the cohort were institutionalization longer than 3 months or death. The profile of the professional caregivers depended on the type of intervention (occupational therapists, physiotherapists, nurses or psychologists) and they all followed two days and a half training to assess with the interRAI HC.

\section{Data Analysis}

After searching the scientific literature on risk determinants of falls (Feldman \& Chaudhury, 2008; Fletcher, P. C. \& Hirdes, 2002; Tinetti et al., 1995) and checking the interRAI HC instrument, a total of 28 items were selected and tested such as unsteady gait, visual problems, sleeping problems, cognitive functioning, mobility, foot problems, use of walking aid material, living situation, etc. In order to answer the first research question (aim 1), univariate analyses using Wilcoxon rank and Mann-Whitney tests for continuous variables and proportion tests for dichotomous variables were first applied to the sample in order to explore whether there were significant differences between the populations (people who fell or not in the first six months of follow-up). Subsequently, correlation analyses were performed in order to determine the risk factors associated with falls in older people, with no falls up until 90 days before they started participating in the intervention (sample 1), but who fell in the first 6 months of followup, as compared to people who did not fall. A multivariate logistic analysis was then performed in order to identify the risk factors of falls with the most significant associations.

A second part of the analysis aiming at exploring the second research question (aim 2) dealt with the population who fell in the 3 months before receiving the home care interventions 
(sample 2), in order to determine whether home modifications by an occupational therapist would have an effect in the risk of recurrent falls between baseline and 6 months. Bivariate analysis was first performed to determine which factors were correlated with the risk of falling. The factors highlighted as significant by the bivariate analysis were subsequently analyzed by multivariate analysis in order to determine which types of intervention are associated with less falls. This was important because people in the different groups might have a different risk for falls. Controlling for these factors was necessary when calculating the association between receiving an intervention and the incidence of recurrent falls. All calculations were made with STATA 11.1.

\section{Results}

\section{Risk factors for falls in people with no prior falls (sample 1)}

The first sub-sample consisted of 4538 frail older persons who did not fall in the last 90 days before receiving the home care intervention (average age $=80.7 \pm 6.86$, female gender: 66.01\%). A total of 1412 people (31\%) could not be evaluated because of a lack of a second assessment due to a period of less than 6 months receiving the intervention (caused by death, exit from the intervention and no second assessment or admission to long term care facilities) or because the assessment was incomplete. Of the remaining 3126 persons, 286 (9.15\%) fell between the first and the second evaluation (during the first 6 months of follow-up). Between the population of people who fell before baseline and those who did not fall before baseline, no significant differences were found according to age and gender. Of the 28 variables selected, only the variables shown in table 1 had a significant association with the risk of falls during the first 6 months in the intervention: vision problems, stress in the last 90 days, sleeping problems, need of more informal support (CAP Informal Support), informal caregiver does not live with the older person, distress of informal caregiver, informal caregiver's support, and incapability 
of the informal caregiver to continue giving care to the older person. The items from the interRAI HC 'being long period of time alone' and 'presence of an informal caregiver' also showed to be significantly associated with falls, but had to be removed from the analysis due to collinearity with respectively the variable 'informal caregiver lives with older person' and the CAP Informal Support. The CAP Informal Support detects older people who generally have difficulties in everyday life activities and live alone, or who do not have sufficient informal support. 
Table 1. Variables correlating significantly to falls in the first six months in the intervention in Sample 1 (significance tests for proportions and confirmed by bivariate analysis) $(n=3126)$

Variables

\begin{tabular}{|c|c|}
\hline $\begin{array}{l}\text { People who fell in } \\
\text { first } 6 \text { months } \\
n=286 \text { (average age }\end{array}$ & fall in first 6 \\
\hline $\begin{array}{l}79.4, \\
\text { female) }\end{array}$ & $\begin{array}{l}\text { age } 78.7,66 \\
\text { female) }\end{array}$ \\
\hline
\end{tabular}

Vision problem Yes

$7.29 \%[0.04 ; 0.11]$

$3.64 \%[0.03 ; 0.04]$

0.005

Stress in last 90 days

Yes

$34.05 \%[0.29 ; 0.39]$

$28.27 \%[0.27 ; 0.30]$

$0.042 *$

Sleeping problems

Yes

$34.43 \%[0.29 ; 0.40]$

$28.66 \%[0.27 ; 0.30]$

$0.046 *$

Insufficient informal support

(CAP Informal Support)

$47.32 \%[0.41 ; 0.54] \quad 39.15 \%[0.37 ; 0.41] \quad \mathbf{0 . 0 1 3} *$

Informal caregiver lives with client

No

$68.39 \%[0.62 ; 0.74] \quad 80.88 \%[0.79 ; 0.83] \underset{* * *}{\mathbf{0 . 0 0 0}}$

Distress of informal caregiver

Yes

$22.81 \%[0.17 ; 0.28] \quad 15.37 \%[0.14 ; 0.17]$

0.004

***

Informal caregiver unsatisfied with support

Yes

$14.98 \%[0.10 ; 0.19] \quad 10.51 \%[0.09 ; 0.12] \quad \mathbf{0 . 0 4 0} *$

Informal caregiver can continue in future

No

$34.78 \%[0.29 ; 0.41] \quad 27.46 \%[0.26 ; 0.29]$

$0.019 *$ 
In Table 2, the logistic regression model for incidence of falls during the first 6 months of follow-up showed vision problem, distress of informal caregiver and insufficient informal care as the main predictors of falls at 6 months (Table 2). Vision problems were strongly associated with an increased risk of falling as indicated by an odds ratio (OR) of 3.06. Seniors who lived with an informal caregiver who was distressed were 1.93 times more likely to experience a fall and those who had insufficient informal support (CAP Informal Support triggered $)$ were at greater risk of falling $(\mathrm{OR}=1.63)$.

Table 2. Logistic Regression Model for Risk of Falling in Sample 1 $(\mathrm{n}=3126)$

\begin{tabular}{|c|c|}
\hline Independent Variables & $\begin{array}{c}\text { Odds Ratios } \\
\text { (Confidence } \\
\text { Intervals) }\end{array}$ \\
\hline Vision problems & \\
\hline Yes & $3.02(1.68-5.46) * * *$ \\
\hline Stress in last 90 days & \\
\hline Yes & $1.17(0.81-1.67)$ \\
\hline Sleeping problems & \\
\hline Yes & $1.27(0.89-1.82)$ \\
\hline Distress of informal caregiver & \\
\hline Yes & $1.98(1.25-3.15)^{* *}$ \\
\hline $\begin{array}{l}\text { Informal caregiver is satisfied with support } \\
\text { No }\end{array}$ & $0.97(0.57-1.64)$ \\
\hline $\begin{array}{c}\text { Informal caregiver can continue in future } \\
\text { No }\end{array}$ & $1.03(0.70-1.51)$ \\
\hline Insufficient informal support & \\
\hline Yes & $1.63(1.08-2.48)^{*}$ \\
\hline $\begin{array}{l}\text { Informal caregiver lives with client } \\
\text { Yes }\end{array}$ & $0.96(0.77-1.20)$ \\
\hline
\end{tabular}




\section{Effect of home modifications on risk of falling in people who already fell (Sample 2)}

The second sample consisted of 1565 people (average age $=81.78 \pm 6.79$, female gender: $70.43 \%$ ) who fell in the last 90 days before baseline. Of these, $72 \%$ of older persons had fallen again at least once during the first six months of follow-up. Bivariate analyses showed that only three variables out of 28 correlated significantly with risk of falling (no falls at follow-up vs at least one fall at follow-up). These were the use of walking aid material, the CAP Falls and Informal caregiver lives or not with the older person. 
Table 3. Logistic Regression Model for Impact of Home Care Interventions on Risk of Falling, Sample 2 ( $\mathrm{n}=1406)$

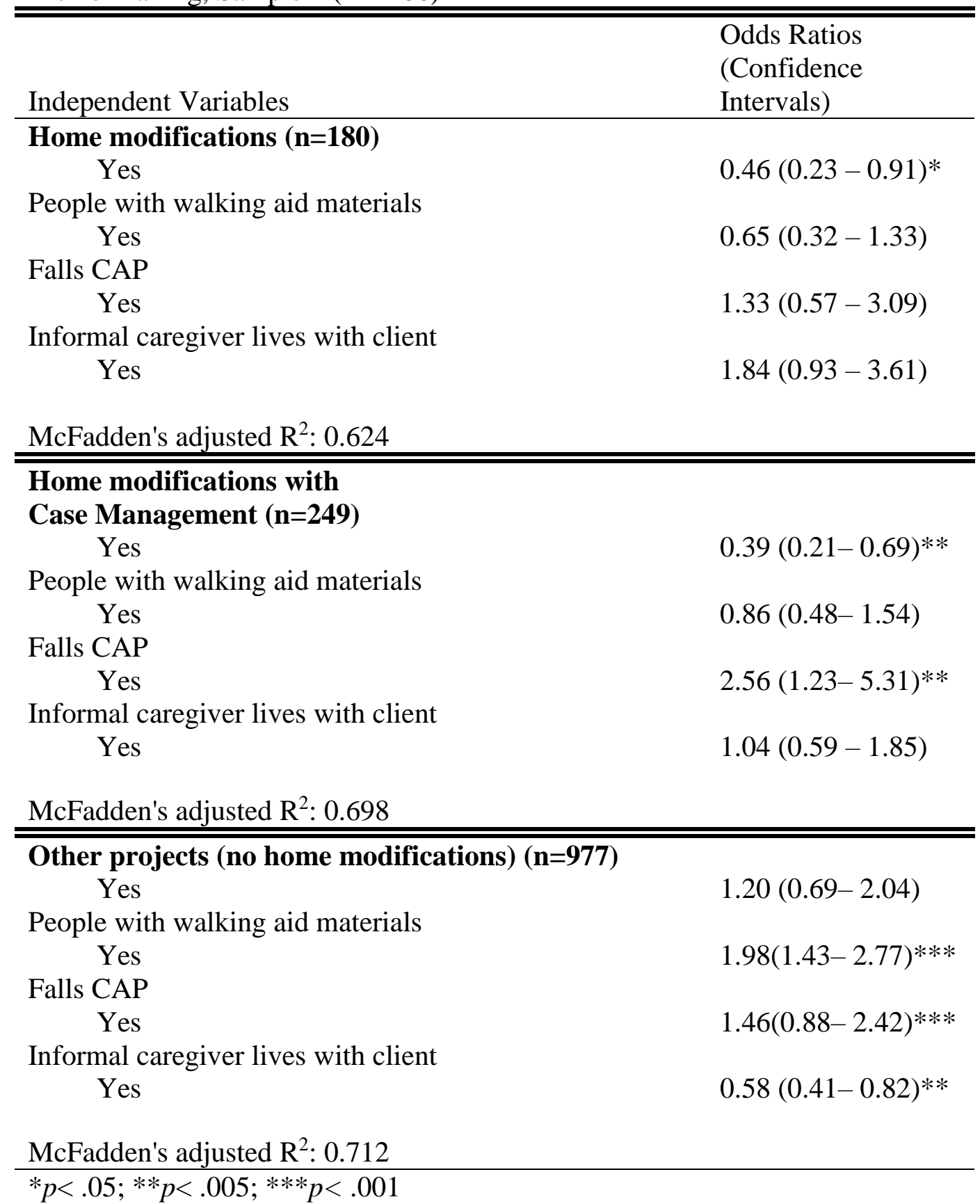


The first logistic regression model showed that older persons receiving from home modifications provided by an occupational therapist had a lower chance of falling in the next 6 months $(\mathrm{OR}=0.46)$ when compared to people in the control group. This is the only significant factor in the first logistic regression model. The second model showed similar results for interventions combining case management and home modifications $(\mathrm{OR}=0.39)$. The Falls CAP showed to be a high significant risk factor for falling with an OR of 2.56 indicating people with a higher chance of falling. This CAP had a higher value for people with more than one fall in the last 3 months. The third logistic regression model showed no impact from projects providing other types of interventions than home modification $(\mathrm{OR}=1.20)$. However, this model underlined the importance of the informal caregiver who lives with the older person, since the risk of falls was reduced $(\mathrm{OR}=0.58)$. It also showed an increase of the risk of falls when the patient has the Falls CAP triggered $(\mathrm{OR}=1.46)$ and especially when frail older persons made use of walking aid materials $(\mathrm{OR}=1.98)$.

\section{Discussion}

The main predictors of falls in this study were vision problems, distress of informal caregiver and insufficient informal support. Occupational therapy intervention that included home modifications showed a significant reduction of falls at six month combined or not with a case management component.

The population investigated for the study on the risk factors was frail older adults without previous falls. The most significant risk factors for falls identified by the bivariate analysis and logistic regression were vision problems and problems with informal care (informal caregiver's distress and the Informal Support CAP). Staying longer at home is promoted by the Belgian government, as well as in other countries. This is only possible when informal care is sufficiently supported. Other studies have shown that the general health of the informal caregiver influences 
the outcomes of older persons (hospital admissions, emergency department visits, institutionalization, quality of life) (Bookwala et al., 2004; Kuzuya et al., 2011; Miller, Rosenheck, \& Schneider, 2011; Reckrey, DeCherrie, Kelley, \& Ornstein, 2013). The analyses show this also applies to the risk of falling. Sufficient informal care, by a caregiver who is not overwhelmed, had a positive impact on the risk of falling. In other words, the daily presence of an informal caregiver could be an asset, but could also have adverse effects in case this caregiver shows symptoms of distress - which can contribute to a higher chance of fall incidence $(\mathrm{OR}=$ 1.98).

Vision problems such as glaucoma, cataract, and age related macular degeneration greatly increased the risk of falling $(\mathrm{OR}=3.02)$. This was also mentioned in other studies (Balzer, Bremer, Schramm, Luhmann, \& Raspe, 2012; Chang \& Do, 2015; Gillespie et al., 2012; Prudham \& Evans, 1981; World Health Organization, 2007) and visual problems increase with age (Carter, 1994). An impaired vision makes the environment more hostile, and the probability of the client getting hurt becomes higher. Moreover, it appears that reduced vision may be a predisposing factor to postural imbalance (Lord, 2006).

A fall in itself is predictive for a subsequent fall (Fletcher, Berg, Dalby, \& Hirdes, 2009), and the choice of the first sample without previous falls $(n=3126)$ was made to bring out the factors associated with falls while isolating the risk coming from a previous fall incidence. The results outline the risk factors of falls for the group who had previously no risk coming from previous falls.

A second sample was constructed including only people who fell in the 90 days before they entered the project. For this sample who fell before baseline $(\mathrm{N}=1565)$, the logistic regression models highlighted that home modifications by an occupational therapist in the living environment of a frail older person was associated with a decrease in falls when compared to 
the control group $(\mathrm{OR}=0.46)$ in the first 6 months of follow-up. This was also the case for interventions providing case management combined with home modifications $(\mathrm{OR}=0.39)$. For the older people not receiving any home modifications, the risk of falls was not significant $(\mathrm{p}>0.05)$. These results are congruent with other studies about effectiveness of home modifications. Home modification was shown to be associated with a reduction in the risk of fall at six months and over (Clemson, Mackenzie, Ballinger, Close, \& Cumming, 2008; Cumming et al., 1999; Rao, 2005) in combination or not with other interventions such as case management. The benefit differs only to a limited extent when comparing projects that only provide occupational therapy at home $(\mathrm{OR}=0.46)$ and projects which offer occupational therapy combined with case management support $(\mathrm{OR}=0.39)$. That could mean that case management has an impact but not very large on the reduction of the risk of falls while the home modifications by an occupational therapist had the main effect. Furthermore, the fact that home modifications are done by an occupational therapist exclusively increases the efficiency of this intervention (Gillespie et al., 2012; Pighills et al., 2011). According to the International Handbook of Occupational Therapy Interventions this is the result of the ability of the occupational therapist as a professional to identify the hazards related to the environment and the behaviours making the risks of falls higher and propose ad hoc solutions (Gitlin, 2015).

However, in order to be the most efficient, home modification cannot be limited to only advice, which in itself does not suffice. In our study, home modifications interventions started with a thorough evaluation of the person's situation by means of the interRAI HC instrument and then a care plan was made based on the results of the assessment. This assessment can help to plan home modifications because it not only assesses the clinical situation of the client but also the client's social situation and his/her environment as well. An ideal process of the intervention would be: first, an evaluation is made of the person's wishes and needs according 
to the situation they are in (strengths, weaknesses and risks) using this comprehensive instrument; then, adaptations are advised and realized based on this evaluation, and third the person and his informal caregiver receive training and education on use of the adaptations (Chase, Mann, Wasek, \& Arbesman, 2012; Feldman \& Chaudhury, 2008). Home modifications should thus be a process which combines several crucial interventions (Stark et al., 2009). An advantage of this process is the duration of its effects. Our analyses target the first six months of an intervention, other articles highlighted long term effects of one year (Pighills et al., 2011) to two year (Stark et al., 2009) interventions. This means that home modifications can reduce the risk of falls, which was also highlighted in our study, but clients should have longer followup in order to achieve greater or more effective outcomes of the intervention over time. Besides having a positive effect on falls, home modifications also have an effect in fields where rehabilitation therapies, particularly important in acute situations, may have some limits. Indeed, home modifications are not only about targeting any lesion or pathologies like rehabilitation therapies do but home modifications deal also with their consequences (disability and handicap they cause) either in the form of prevention or in stabilization phase when a functional recovery does not seem to be possible (Permsirivanich et al., 2009). So, for frail older persons for whom physical exercises programs do not seem useful in terms of reduction of the risk of falls, home modifications may be the best alternative (Balzer et al., 2012).

\section{Strengths}

Compared to other similar studies (Currin et al., 2012; Gitlin et al., 2006; Johnston et al., 2010; Petersson, Kottorp, Bergstrom, \& Lilja, 2009), the sample size in this study was higher, which allowed the identification of risk factors of falls and to demonstrate the effectiveness of home modifications by an occupational therapist. Another strength was the use of a holistic instrument such as the interRAI HC, which made possible to check different types of variables 
and include them in the bivariate and multivariate analysis. Also noticeable was the variety of types of interventions for which we could compare the impact on the risk of falls, such as interventions providing home modifications and interventions providing home modifications in combination with case management and other types providing no home modifications.

\section{Limitations}

Some studies included diseases such as arthritis, diabetes and the use of certain types of medication as predictive of falls (Chang \& Do, 2015; Fletcher \& Hirdes, 2002). These findings however could not be validated in the current study due to lack of accuracy in the medication list provided by the caregivers. Since caregivers had sometimes difficulties to provide the full medication list and list of diagnoses, this resulted in missing values.

This evaluation targeted frail older people receiving from home care interventions. So, identified factors for incidence of falls have been identified as predictors of falls with the presence of an intervention. The control group was also receiving interventions but these were identified as the least effective and the closest to not doing anything. In addition, the fact that $31 \%$ of the total sample (in intervention group and control group) could not be analyzed due to lack of follow-up assessment (less than 6 months receiving the intervention) or due to incomplete follow-up assessments posed a challenge to the analysis and a potential bias. Strategies to overcome this bias should be planned and studied in the future.

\section{Conclusion}

In the absence of a previous fall that raises the risk of falling, the main predictors of falls in this study were vision problems, distress of informal caregiver and insufficient informal support.

As confirmed by other studies (Clemson et al., 2008; Cumming et al., 1999; Rao, 2005), a home modification by an occupational therapist reduces the fall risk of frail older persons. The 
analysis showed a decrease in falls for people receiving interventions offering only home modifications by an occupational therapist $(\mathrm{OR}=0.46)$ and projects providing home modifications combined with case management support $(\mathrm{OR}=0.39)$. In comparison to this, projects offering no home modification did not seem to decrease the risk of falls $(\mathrm{OR}=1.20)$.

The intervention of an occupational therapist to prevent falls seems to be efficient in the first six months after baseline with the use of a home modification process which includes a client-centered approach thanks to a risk and needs evaluation as well as a home adaptations follow-up to educate a client on how to correctly use material aids. Therefore home modifications may contribute to improve the older persons' quality of life and maintain older persons longer at home.

In Belgium $24 \%$ of people 65 or older fall at least once (Demarest, Drieskens, Gisle, Van der Heyden, \& Tafforeau, 2010). Knowing that the intervention of an occupational therapist can significantly reduce the risk of falls, the benefit in terms of health and financial consequences saved may be really interesting for frail older people, their family and for the entire society.

\section{Conflict of Interest}

The authors declare no conflict of interest.

\section{Key messages}

1. First, informal caregiver support in an essential way to influence the fall risk of frail older persons.

2. Home modification or advice by an occupational therapist can help to avoid falls and consists of an intervention that is less invasive and restrictive than medication. Although we do not address this in the article, home modification can be a first step in the prevention of falls before more invasive measures can be started. Moreover the impact of home modifications 
combined with case management on the reduction of the risk of fall also significant although the impact is not much higher by adding the case management intervention.

3. Home modifications can be efficient but they should follow a process that does not only consist of a simple advice about aid materials. The modifications and advices should be based on the following steps:

- An evaluation of the client's demands and needs by a comprehensive assessment such as the interRAI HC instrument, in order to identify their strengths, weaknesses and risks;

- Adaptations resulting from the evaluation;

- An education of the client and the informal caregiver in terms of follow-up and in terms of use of the new type of help, but also to take the most advantage of it in order to guarantee its effectiveness.

\section{References}

Anderson, L. A., Goodman, R. A., Holtzman, D., Posner, S. F., \& Northridge, M. E. (2012). Aging in the United States: opportunities and challenges for public health. American Journal of Public Health, 102(3), 393-395. doi:10.2105/AJPH.2011.300617

Andresen, M., \& Puggaard, L. (2008). Autonomy among physically frail older people in nursing home settings: a study protocol for an intervention study. BMC Geriatrics, 8, 32. doi:10.1186/1471-2318-8-32

Balzer, K., Bremer, M., Schramm, S., Luhmann, D., \& Raspe, H. (2012). Falls prevention for the elderly. GMS Health Technology Assessment, 8, Doc01. doi:10.3205/hta000099 
Bookwala, J., Zdaniuk, B., Burton, L., Lind, B., Jackson, S., \& Schulz, R. (2004). Concurrent and long-term predictors of older adults' use of community-based long-term care services: the caregiver health effects study. Journal of Aging and Health, 16(1), 88-115. doi: $10.1177 / 0898264303260448$

Cameron, I. D., Murray, G. R., Gillespie, L. D., Robertson, M. C., Hill, K. D., Cumming, R. G., \& Kerse, N. (2010). Interventions for preventing falls in older people in nursing care facilities and hospitals. Cochrane Database of Systematic Reviews, (1), CD005465. doi:10.1002/14651858.CD005465.pub2

Carpenter, G. I. (2006). Accuracy, validity and reliability in assessment and in evaluation of services for older people: The role of the interRAI MDS assessment system. Age Ageing, 35, 327-329. doi:10.1093/ageing/af1038

Carter, T.L. (1994). Age-related vision changes: a primary care guide. Geriatrics, 49(9), 37-42. Retrieved from http://europepmc.org/abstract/med/8088558

Chang, V. C., \& Do, M. T. (2015). risk factors for falls among seniors: implications of gender. American Journal of Epidemiology, 181. doi: 10.1093/aje/kwu268

Chase, C. A., Mann, K., Wasek, S., \& Arbesman, M. (2012). Systematic review of the effect of home modification and fall prevention programs on falls and the performance of community-dwelling older adults. American Journal of Occupational Therapy, 66(3), 284-291. doi:10.5014/ajot.2012.005017

Clemson, L., Mackenzie, L., Ballinger, C., Close, J. C. T., \& Cumming, R. G. (2008). Environmental interventions to prevent falls in community-dwelling older people: a meta- 
analysis of randomized trials. Journal of Aging and Health, 20(8), 954-71. doi: $10.1177 / 0898264308324672$

Cumming, R. G., Thomas, M., Szonyi, G., Frampton, G., Salkeld, G., \& Clemson, L. (2001). Adherence to occupational therapist recommendations for home modifications for falls prevention. The American Journal of Occupational Therapy: Official Publication of the American Occupational Therapy Association, 55(6), 641-8. Retrieved from http://www.ncbi.nlm.nih.gov/pubmed/12959228

Cumming, R. G., Thomas, M., Szonyi, G., Salkeld, G., O’Neill, E., Westbury, C., \& Frampton, G. (1999). Home visits by an occupational therapist for assessment and modification of environmental hazards: a randomized trial of falls prevention. Journal of the American $\begin{array}{lllll}\text { Geriatrics } & \text { Society, } & \text { 47(12), } & \text { 1397-402. } & \text { Retrieved }\end{array}$ http://www.ncbi.nlm.nih.gov/pubmed/10591231

Currin, M. L., Comans, T. A., Heathcote, K., \& Haines, T. P. (2012). Staying safe at home. Home environmental audit recommendations and uptake in an older population at high risk of falling. Australasian Journal on Ageing, 31(2), 90-95. doi:10.1111/j.17416612.2011.00545.x

Demarest, S., Drieskens, S., Gisle, L., Van der Heyden, J., \& Tafforeau, J. (2010). Enquête de santé, 2008. Rapport VI - La Santé des Personnes Agées. Retrieved from http://www.socialsecurity.fgov.be/docs/fr/publicaties/gezondheid-ouderen-rapport-VI-2008fr.pdf

Feldman, F., \& Chaudhury, H. (2008). Falls and the physical environment: a review and a new multifactorial falls-risk conceptual framework. Canadian Journal of Occupational 
Therapy. Revue Canadienne D'ergothérapie, 75(2), 82-95. Retrieved from http://www.ncbi.nlm.nih.gov/pubmed/18510252

Ferrucci, L., Giallauria, F., \& Guralnik, J. M. (2008). Epidemiology of aging. Radiologic Clinics of North America, 46(4), 643-52, v. doi:10.1016/j.rcl.2008.07.005

Fletcher, P. C., Berg, K., Dalby, D. M., \& Hirdes, J. P. (2009). Risk factors for falling among community-based seniors. Journal of Patient Safety, 5(2), 61-66.

Fletcher, P. C., \& Hirdes, J. P. (2002). Risk factors for falling among community-based seniors using home care services. Journal of Gerontology series A: Biological Sciences and Medical Sciences, $\quad 57(8), \quad$ M504-10. $\quad$ Retrieved from http://www.ncbi.nlm.nih.gov/pubmed/12145363

Fontaine, L., \& Jans, B. (2009). Enquête de satisfaction dans les maisons de repos et dans les maisons de repos et de soins-2007. Retrieved from https://www.wivisp.be/nsih/download/nursing_homes/Satis_2007_final_FR.pdf

Gillespie, L. D., Robertson, M. C., Gillespie, W. J., Lamb, S. E., Gates, S., Cumming, R. G., \& Rowe, B. H. (2009). Interventions for preventing falls in older people living in the community. Cochrane Database of Systematic Reviews, (2), CD007146. doi:10.1002/14651858.CD007146.pub2

Gillespie, L. D., Robertson, M. C., Gillespie, W. J., Sherrington, C., Gates, S., Clemson, L. M., \& Lamb, S. E. (2012). Interventions for preventing falls in older people living in the community. Cochrane Database of Systematic Reviews, 9, CD007146. doi:10.1002/14651858.CD007146.pub3 
Gitlin, L.N. (2015). Environmental adaptations for individuals with functional difficulties and their families in the home and community. In I. Söderback, International Handbook of Occupational Therapy Interventions (2nd ed., pp. 165-176). Stockholm, Sweden: Springer. Retrieved from https://books.google.com/books?id=o4qaBQAAQBAJ\&pgis=1

Gitlin, L. N., Hauck, W. W., Winter, L., Dennis, M. P., \& Schulz, R. (2006). Effect of an in-home occupational and physical therapy intervention on reducing mortality in functionally vulnerable older people: preliminary findings. Journal of the American Geriatrics Society, 54(6), 950-955. doi:10.1111/j.1532-5415.2006.00733.x

Grimshaw, J., Campbell, M., Eccles, M., \& Steen, N. (2000). Experimental and quasiexperimental designs for evaluating guideline implementation strategies. Family Practice, 17 Suppl 1, S11-6. doi: 10.1093/fampra/17.suppl_1.S11

Hirdes, J. P., Ljunggren, G., Morris, J. N., Frijters, D. H. M., Finne Soveri, H., Gray, L., Björkgren, M., \& Gilgen, R. (2008). Reliability of the interRAI suite of assessment instruments: a 12-country study of an integrated health information system. BMC Health Services Research, 8, 277. doi:10.1186/1472-6963-8-277

Inouye, S. K., Studenski, S., Tinetti, M. E., \& Kuchel, G. A. (2007). Geriatric syndromes: clinical, research, and policy implications of a core geriatric concept. Journal of the American Geriatrics Society, 55(5), 780-91. doi:10.1111/j.1532-5415.2007.01156.x

Johnston, K., Barras, S., \& Grimmer-Somers, K. (2010). Relationship between predischarge occupational therapy home assessment and prevalence of post-discharge falls. Journal of Evaluation in Clinical Practice, 16(6), 1333-1339. doi:10.1111/j.1365-2753.2009.01339.x 
Karlsson, M. K., Magnusson, H., von Schewelov, T., \& Rosengren, B. E. (2013). Prevention of falls in the elderly-a review. Osteoporosis International. doi: 10.1007/s00198012-2256-7

Kuzuya, M., Enoki, H., Hasegawa, J., Izawa, S., Hirakawa, Y., Shimokata, H., \& Akihisa, I. (2011). Impact of caregiver burden on adverse health outcomes in communitydwelling dependent older care recipients. The American Journal of Geriatric Psychiatry: Official Journal of the American Association for Geriatric Psychiatry, 19(4), 382-91. doi:10.1097/JGP.0b013e3181e9b98d

Landi, F., Tua, E., Onder, G., Carrara, B., Sgadari, A., Rinaldi, C., Gambassi, G., Lattanzio, F., \& Bernabei, R. (2000). Minimum data set for home care: a valid instrument to assess frail older people living in the community. Medical Care, 38, 1184-1190.

Lord, S. R. (2006). Visual risk factors for falls in older people. Age and Ageing, 35 Suppl 2(suppl_2), ii42-ii45. doi:10.1093/ageing/afl085

Masud, T., \& Morris, R. O. (2001). Epidemiology of falls. Age and Ageing, 30, 3-7. doi:10.1093/ageing/30.1.3

Miller, E. A., Rosenheck, R. A., \& Schneider, L. S. (2011). Caregiver burden, health utilities, and institutional service use in Alzheimer's disease. International Journal of Geriatric Psychiatry, 27(4), n/a-n/a. doi:10.1002/gps.2730

Peel, N. M. (2011). Epidemiology of Falls in Older Age. Canadian Journal on Aging / La Revue Canadienne Du Vieillissement. doi:10.1017/S071498081000070X 
Permsirivanich, W., Tipchatyotin, S., Piravej, K., Juntawises, U., Kuptniratsaikul, V., \& Ma-A-Lee, A. (2009). Factors influencing home modification of stroke patients. Journal of the Medical Association of Thailand $=$ Chotmaihet Thangphaet, 92(1), 101-7. Retrieved from http://www.ncbi.nlm.nih.gov/pubmed/19260250

Petersson, I., Kottorp, A., Bergstrom, J., \& Lilja, M. (2009). Longitudinal changes in everyday life after home modifications for people aging with disabilities. Scandinavian Journal of Occupational Therapy, 16(2), 78-87. doi:10.1080/11038120802409747

Petersson, I., Lilja, M., Hammel, J., \& Kottorp, A. (2008). Impact of home modification services on ability in everyday life for people ageing with disabilities. Journal of Rehabilitation Medicine, 40(4), 253-260. doi:10.2340/16501977-0160

Pighills, A. C., Torgerson, D. J., Sheldon, T. A., Drummond, A. E., \& Bland, J. M. (2011). Environmental assessment and modification to prevent falls in older people. Journal of the American Geriatrics Society, 59(1), 26-33. doi:10.1111/j.1532-5415.2010.03221.x

Prudham, D., \& Evans, J. G. (1981). Factors associated with falls in the elderly: a community study. Age and Ageing, 10(3), 141-6. Retrieved from http://europepmc.org/abstract/med/7270321

Rao, S. S. (2005). Prevention of falls in older patients. American Family Physician, 72(1), 81-8. Retrieved from http://www.ncbi.nlm.nih.gov/pubmed/16035686

Reckrey, J. M., DeCherrie, L. V., Kelley, A. S., \& Ornstein, K. (2013). Health Care Utilization among homebound elders: does caregiver burden play a role? Journal of Aging and Health, 25(6), 1036-1049. doi:10.1177/0898264313497509 
Rubenstein, L. Z. (2006). Falls in older people: Epidemiology, risk factors and strategies for prevention. In Age and Ageing (Vol. 35). doi:10.1093/ageing/afl084

Stark, S., Landsbaum, A., Palmer, J. L., Somerville, E. K., \& Morris, J. C. (2009). Clientcentred home modifications improve daily activity performance of older adults. Canadian Journal of Occupational Therapy, 76 Spec No, 235-245. Retrieved from http://www.ncbi.nlm.nih.gov/pubmed/19757729

Strandberg, T. E., Pitkälä, K. H., Tilvis, R. S., O’Neill, D., \& Erkinjuntti, T. J. (2013). Geriatric syndromes--vascular disorders? Annals of Medicine, 45(3), 265-73. doi:10.3109/07853890.2012.727022

Tanner, B., Tilse, C., \& de Jonge, D. (2008). Restoring and sustaining home: the impact of home modifications on the meaning of home for older people. Journal of Housing For the Elderly, 22(3), 195-215. doi:10.1080/02763890802232048

Tinetti, M. E., Doucette, J., Claus, E., \& Marottoli, R. (1995). Risk factors for serious injury during falls by older persons in the community. Journal of the American Geriatrics Society, 43(11), 1214-1221. doi: 10.1111/j.1532-5415.1995.tb07396.x

Tinetti, M. E., Liu, W. L., \& Ginter, S. F. (1992). Mechanical restraint use and fallrelated injuries among residents of skilled nursing facilities. Annals of Internal Medicine, 116(5), 369-374. doi: 10.7326/0003-4819-116-5-369

Trottier, H., Martel, L., Houle, C., Berthelot, J. M., \& Legare, J. (2000). Living at home or in an institution: what makes the difference for seniors? Health Reports, 11(4), 49-61 (Eng); 55-68 (Fre). Retrieved from http://www.ncbi.nlm.nih.gov/pubmed/10879330 
Vanneste, D., \& Declercq, A. (2014). The development of BelRAI, a web application for sharing assessment data on frail older people in home care, nursing homes and hospitals. In Achieving Effective Integrated E-Care Beyond the Silos (Beyond Sil.). Hershey. doi: 10.4018/978-1-4666-6138-7.ch010

Reference has been removed for blinding

Walker, J.E., \& Howland, J. (1991). Falls and fear of falling among elderly persons living in the community: occupational therapy interventions. American Journal of Occupational Therapy, 45(2), 119-122. doi:10.5014/ajot.45.2.119

World Health Organization. (2007). WHO global report on falls prevention in older age. Retrieved from World Health Organization Website: http://www.who.int/ageing/publications/Falls_prevention7March.pdf?ua=1

Reference has been removed for blinding 